\title{
Non-Union Current Treatment Concept
}

\author{
Arash Moghaddam, ${ }^{1, *}$ Claudia Ermisch, ${ }^{1}$ and Gerhard Schmidmaier ${ }^{1}$ \\ ${ }^{1}$ Center for Orthopedics, Trauma and Spinal Cord Injury, University Hospital Heidelberg, Heidelberg, Germany \\ *Corresponding author:Arash Moghaddam, Center for Orthopedics, Trauma and Spinal Cord Injury, University Hospital Heidelberg, Heidelberg, Germany. Tel: +49-62215635394, Fax: \\ +49-62215629123, E-mail:Arash.Moghaddam@med.uni-heidelberg.de
}

Received 2015 October 31 ; Accepted 2015 December 25.

\begin{abstract}
Context: This article wants to give a current concept for the challenging decision for conservative or operative treatment strategies of nonunions according to the principles of 'diamond concept' and aspects that have to be attended.

Evidence Acquisition: Between February 2010 and March 2014, 424 patients with non-unions were treated at Heidelberg university hospital. This database has been analyzed at least one year after the treatment. The analysis and the experience in surgery and treatment of non-unions as well as present literature were prepared for this review as a current concept.

Results: If an atrophic non-union is suggested, reosteosynthesis and biological stimulation is required. A revision surgery of autologous transplantation of cancellous bone from the iliac crest is often enough. Alternatively, reamer-irrigator-aspirator (RIA) can be taken out of the femur with lower complications and pain in the extraction area and be combined with growth factors like bone morphogenetic proteins (BMPs), if consolidation after cancellous bone is still absent. In complex cases, consequential and radical removal of the infection often improved circulation through interventional angiography and use of the two-step procedure (the Masquelet technique) as well as a tissue covering are required.

Conclusions: By using the 'diamond concept' as a complex concept, non-unions can be treated in different stages in a targeted manner.
\end{abstract}

Keywords: Diamond Concept, Reamer-Irrigator-Aspirator, Non-Union, Masquelet Technique

\section{Context}

The percentage of delayed or non-union after fractures of long bones is approximately $10 \%$, but depends on patient's risk profile. The current definition states that a non-union is a fracture that will not consolidate without any further intervention, independent of the treatment time. With adequate stability, conservative treatment in the early stages of a non-union is possible. The operative treatment depends on the type of non-union. There are one-step or two-step procedures according to the principles of the 'diamond concept'. This involves the improvement of the mechanical situation (in most cases with a reosteosynthesis) and vascularization, local application of osteoconductive carriers e.g. tricalciumphosphate, vital cells from autologous bone, and osteoinductive substances like bone morphogenetic proteins (BMP-2 or BMP-7).

Hypertrophic and atrophic non-unions without large defect gaps or signs of infection can be treated with a one-step procedure. For treating infected non-unions or non-unions with large defect gaps, the Masquelet technique is recommended.

\section{Evidence Acquisition}

University of Heidelberg hospital is the major center for orthopaedic treatments in Germany. This database has been analyzed at least one year after treatment. Our results were on one hand based on a collective of 424 patients with non-unions who were treated in our center between February 2010 and March 2014, and on the other hand they were based on the current literature on e.g. PubMed. The analysis and the experience in surgery and treatment of non-unions as well as present literature were prepared for this review as a current concept.

\section{Results}

\subsection{Epidemiology}

In general, non-union as a complication of fracture healing occurs in $5 \%-10 \%$ of cases (1) and can be as high as $30 \%$ in high-risk groups (2-5).

The high incidence on the tibia can be explained by poor tissue covering and therefore poor blood circulation. In addition, there is more often $2^{\circ}-3^{\circ}$ of open injuries with complex damage of the bone and the surrounding soft tissue (5). The incidence of non-unions in bones of the extremities is as follows: the tibia has on average an occurrence of $8.7 \%(6,7)$, the femur only slightly less at $6.1 \%(8-10)$, the humerus 3\% - 5\%, and the lower arm 5\% (11-18).

According to the data in our non-union register, there is a greater presence of non-unions in male patients between the ages of 30 and 50 years.

Copyright ( ) 2016, Iran University of Medical Sciences. This is an open-access article distributed under the terms of the Creative Commons Attribution-NonCommercial 4.0 International License (http://creativecommons.org/licenses/by-nc/4.0/) which permits copy and redistribute the material just in noncommercial usages, provided the original work is properly cited. 


\subsection{Risk Factors}

Besides the type of fracture and the soft tissue damage, there are other risk factors for the development of nonunions (19). Smoking increases the risk of delayed healing or non-unions $(5,20)$. In addition, advanced age has a negative effect on physiological fracture healing $(21,22)$. Other factors such as diabetes mellitus, the use of nonsteroidal anti-inflammatory drugs (NSAIDs) and previous fractures of the same extremity also have negative effects $(23,24)$. In the risk score according to Moghaddam et al. all of these risk factors have their relative importance for measuring the individual risk of a patient for developing a non-union (5) (Table 1).

\subsection{Diagnosis}

The diagnosis begins with extensive history taking and includes the individual risk profile of the patient, taking into account previous illnesses and medications as well as all previous conservative and operative treatments. History of previous infections should be taken into account as well as the analysis of previous clinical and radiological findings. Blood circulation and soft tissue at the site of injury should also be evaluated.

Clinical indications of non-union include pain on weight bearing, limitations to the mobility of an extremity, or instability. In addition, there are clinical signs of infection to be aware of, such as redness, swelling and warmth or development of a fistula. One should especially look out for local, systemic or anamnestic signs of osteitis.

Conventional radiological imaging of the affected extremity in two levels with inclusion of joints is standard for diagnosing faulty positioning or instability. One should note that defects cannot be completely observed with native X-rays due to summation and covering. An additional computed tomography (CT) can be used to evaluate whether there is partial or entire bridging of the defect gap. In addition, a contrast magnetic resonance imaging (MRI) can be used to evaluate vascularization of the bone and separate vital and non-vital areas (25) (A CT scan is considered the gold standard for evaluating nonunions and providing information for treatment).

\subsection{Classification}

According to the current definition from European society of tissue regeneration in orthopedics and traumatology (ESTROT), a non-union is a fracture that does not heal without further intervention, independent of the length of treatment. Non-unions are classically divided into four types: hypertrophic due to mechanical causes, atrophic due to biological causes, defect, and infection non-unions.

Hypertrophic non-unions develop due to insufficient mechanical stability and can lead to formation of a callus in the area of fracture. Bone consolidation does not occur. If therapy is delayed, atrophic non-unions can develop (26). Atrophic non-unions often involve reduced vascularity of the defect gap and surrounding bone, which can lead to atrophy of the fracture ends. Defect non-unions usually occur due to high-speed trauma and higher grade open fractures, which can cause loss of bone through numerous fragments. Furthermore, infected non-unions develop primarily in open fractures after traumas in which germs can get into the wound.

Besides the purely morphological classification, there is a new classification system according to the non-union scoring system (NUSS) which incorporates bone quality, soft tissue damage, and the individual patient risk (e.g. smoking) into a score (27). From this NUSS-score, there are therapy considerations that can be adapted to the patient (28-30). The higher the score, the more specialized and custom the therapy concept must be to offer the possibility of consolidation (Table 2).

\subsection{Therapy}

The goal of non-union therapy is the consolidation of bone defects with correction of the axis and leg length as well as reaching weight bearing stability. A sufficient tissue covering as well as removal of the infection are the basic prerequisites.

Independent of the type of non-union and localization, therapy can differ in conservative and operative approaches.

\subsubsection{Conservative}

Conservative approaches are especially useful in the early phase of non-union treatment and require sufficient mechanical stability as well as bone regeneration potential. The newest methods in conservative treatment in delayed fracture healing of the lower extremity are consequential weight bearing until full weight bearing can be mustered.

The most common methods of conservative treatment in delayed fracture healing in the area of the lower extremity are consequential weight bearing to full weight bearing.

Additionally, fractures are treated with daily lower energy ultrasound (a possibility of conservative therapy is the application of low energy ultrasound to the defect gap), over a defined interval of three to six months.

The deciding criteria for successful treatment with low energy ultrasound are sufficient stability as well as a defect gap of under $10 \mathrm{~mm}$, free of infection in the previous history, start of therapy in less than five months after the fracture, and a NUSS-score less than 35 (31).

\subsubsection{Operative Treatment Diamond Concept}

The multi-factorial causes of delayed fracture healing make an individual patient's specific therapy noteworthy. In this way, the so-called diamond concept (Figure 1) has become evermore established $(3,32)$. Therapy consists of an optimized combination of biological and biomechanical factors $(29,33-38)$ (The diamond concept has five different factors that must be analyzed for therapy) (39).

Non-unions are analyzed according to the following criteria:

- Biomechanical stability; example: through angle stable implants, dynamized medulla nailing. 
- Osteogenic cells: in form of mesenchymal stem cells (MSCs), autologous cancellous bone (iliac crest or reamer irrigator aspirator (RIA)).

- Osteoconductive structures; example: autologous cancellous bone, synthetic bone replacement material (example: tricalcium phosphate).

- Growth hormones; examples: bone morphogenetic protein (BMP)-2 and BMP-7.

- Vascularization: through improving the macro-circulation and local induction of a Masquelet membrane renewal of the fracture ends.

In looking at individual clinical and radiological parameters, there are a number of factors lacking in a combination treatment and therefore, systemic optimization of the biological and biomechanical treatment of nonunions should be looked at $(29,34,40,41)$.

\subsubsection{Isolation of Bone Replacement Material}

The iliac crest often serves as the source of autologous cancellous bone. The method involved is widely used and is considered the gold standard in the surgical treatment of non-unions. It has the optimal consistency and can establish good primary stability as a tricortical graft. Problematic is the limited availability and differing quality and quantity as well as a high extraction morbidity (25, 42-46). An alternative to autologous cancellous bone extraction is the use of RIA (Depuy-Synthes, USA) (Figure 2). In this procedure, the percutaneous opening of the medullary cavity is performed with a combination of drilling, cleaning and vacuum extraction of MSCs out of long bones. This method is primarily performed on the femur, but can also be done on the tibia. In this way, it is possible to extract 80 $\mathrm{cm}$ of the autologous bone material for transplantation $(25,35,43-48)$ (an alternative to extraction of cancellous bone from the iliac crest is the RIA method, which involves winning cancellous bone out of the femur).

There is a larger amount of growth factors (e.g. BMP2 ) in the RIA material as in autologous cancellous bone from the iliac crest. RIA material shows a higher osteoconductive potential in comparison to autologous cancellous bone $(25,46,49,50)$.

\subsubsection{Complications}

The main complications of removal of cancellous bone from the iliac crest are infections, development of hematomas, fractures, hypertrophic scars, and chronic pain from the extraction area (51).

The complications associated with RIA to win autologous bone material are substantially less. In our patient collective, we observed a perforation of the femoral shaft (1/200), which could have been avoided by correctly positioning the guide wire in both levels.

\subsubsection{Growth Factors}

Growth factors play a deciding roll in physiological frac- ture healing and bone regeneration. Currently, there are two growth hormones permitted for use in orthopedics and trauma surgery. These include BMP 2 for open lower leg fractures and BMP-7 for non-unions of the tibia.

Studies over the past years have shown that the use of BMP-7 is at least equal to a single cancellous bone graft (52). Furthermore, there are adequate indications in everyday clinical routine to suggest increases in the healing rate of non-unions (18). The combination of autologous cancellous bone with BMPs is clearly superior to a single cancellous bone graft (53).

BMP-7 is not currently commercially available; so, increased BMP-2 (Medtronic) can be used in non-union therapy.

The authors recommend the additional use of BMPs in a failed therapy with autologous cancellous bone. In addition, when the effect is clearly proven by clinical studies, we recommend receiving approval of costs from the insurance company and approval of its use from a panel of experts.

\subsection{Bone Marrow Drilling in Hypertrophic Non- Unions}

According to the diamond concept, optimizing mechanical stability is indicated in hypertrophic non-unions. In the case of an instable osteosynthesis, a reosteosynthesis is necessary. In simple cases, the dynamization of an adjoining nail with full weight bearing is possible. In complex cases, a reosteosynthesis with medullary cavity drilling and medullary nail osteosynthesis with a thick nail is necessary(54)(in hypertrophic non-unions in the tibia shaft area, medullary cavity drilling and nail osteosynthesis has been indicated).

\subsubsection{Positioning}

A patient is positioned on the back and the $x$-ray beam is positioned on the contralateral side. The placement of a blood tourniquet is not necessary for intramedullary osteosynthesis, but can be necessary for other intervention techniques.

\subsubsection{Execution: Tibia Non-Union}

The knee was bent maximally with the help of orientation points, the tuberositas tibiae and middle of the patella, and the skin was cut. The patellar ligament was cut lengthwise. After the opening of the medullary cavity with an awl, a guide wire was inserted. The correct positioning was tested with the aid of an x-ray intensifier in two levels. The drilling began with the smallest drill and was increased incrementally thereafter. The largest drill was used under intensified image control and was complete only when the drill head had entirely filled the smallest shaft area of the medullary cavity. As a result, the medullary nail can be inserted. This should be $1 \mathrm{~mm}$ less in diameter than maximal drilling.

Because an aseptic non-union can potentially be caused by a low-grade fever, the possibility of using an antibiotic covered nail (e.g. expert tibial nail (ETN) PROtect) can be considered (55). 
Moghaddam A et al.

\subsubsection{Follow-Up}

After wound healing is over, full weight bearing is possible. Up until this point, the patient needs low-dose heparin. For improving the functional outcome, physiotherapy of the bordering joints plays an important role.

\subsection{Atrophic Non-Unions}

Atrophic non-unions are described as insufficient and stagnated bone regeneration. According to the diamond concept, an additional biological activation of bone regeneration is often necessary (In atrophic non-unions, biological activation of bone regeneration is necessary).

\subsubsection{Surgery According to the Diamond Concept}

In the first step, previously implanted osteosynthesis material is completely removed and the proximal and distal ends of the non-union gaps are debrided down to healthy bone. In long bones, debridement should always be expanded to the entire medullary cavity $(29,33,35,46)$. Often a complete implant removal and reosteosynthesis are needed to ensure optimal biomechanical stability and correction of faulty positioning.

After radical debridement of the non-union and reosteosynthesis, defect gaps are filled with autologous cancellous bone in combination with synthetic resorbable material (e.g. tricalciumphosphate) as an osteoconductive scaffold. This can occur in the form of autologous cancellous bone from the iliac crest or through the RIA System from the contralateral femur or tibia. An optimal scaffold should not only be osteoconductive, but also have good cell adhesion capabilities and adequate stability as well as flexibility. The criteria for a good scaffold can be summarized under the 4 F's: form, function, fixation and formation. The currently available material only fulfills these criteria partially (56).

In bone defects under $2 \mathrm{~cm}$ (or $5 \mathrm{~cm}$ ) with no signs of infection, defect gap filling is the only treatment concept used. In larger defects and in the presence of an infection, bone formation involves a two-step method, the Masquelet technique (Figure 3).

The one-step method is contraindicated when there were signs of infection. Furthermore, the age of the patients plays a role as a possible contraindication. The morbidity associated with the procedure should be considered. In some cases, cancellous bone from a donor can be used. Patients with a too narrow medullary cavity of the femur of less than $10 \mathrm{~mm}$ in the isthmus are not right for RIA removal (46).

\subsubsection{Further Bone Replacement Materials}

In addition to allogeneic bone grafts, bone replacement material tricalciumphosphate or growth factors such as BMP-2 or BMP-7 are used (57). This material has osteoinductive and osteconductive effects, which are only present when the surroundings of the non-union are vital and well vascularized.

\subsubsection{Alternative Methods}

In very large bone defects, it must be tested whether bone formation is possible with the Masquelet technique, or if alternatives need to be considered such as callus distraction with an Ilizarov fixator or a vascularized bone transplant or other alternatives.

\subsubsection{Follow-Up}

Follow-up is dependent on the type of executed reosteosynthesis. In the lower extremity, partial weight bearing of $20 \mathrm{~kg}$ for six weeks followed by incremental increases to full weight bearing is recommended.

\subsection{Defect and Infection Non-Unions}

\subsubsection{Bone Formation With the Masquelet Technique}

This technique is used when there is suspicion of infection or a non-union with a defect gap of $>2 \mathrm{~cm}(5 \mathrm{~cm})$. In the first operation, the defect gap is filled with polymethylmethacrylat (PMMA) cement and removal of avital tissue is conducted. In the presence of a known infection, an antibiotic can be mixed with the cement. The PMMA cement should be applied over the bordering vital bone (Figures 3 and 4).

Through a reaction with the cement, the induction of a highly vital membrane similar to natural periost occurs, which is responsible for the circulation of the later transplanted graft material. This first step can be repeated as often as necessary until sanitation of the infection occurs (46).

The adjoining osteosynthesis material should be completely removed if there is suspicion of a previous infection and the extremity should be secured up until the second operation with an external fixator. Adherent bacteria on the implant surface could be observed with a sonication. In this way, the exact microbiological spectrum can be defined and treated with antibiotics. The debrided bone tissue can be evaluated microbiologically and pathologically. If cultures are positive, additional debridement and adaption of local antibiotics is necessary until the infection is cleared (46).

After sanitation of the infection and a four-to-six-week interval, the defect is reconstructed with bone regeneration and in certain cases re-osteosynthesis happens. The constructed Masquelet membrane is opened lengthwise, PMMA cement is removed carefully, and the defect is filled with a combination of MSC-rich autologous cancellous bone (e.g. cancellous bone from the iliac crest or RIA material), tricalcium phosphate (TCP) and an osteoinductive growth factor (e.g. BMP-7 or BMP-2) (58).

\subsubsection{Follow-Up}

As far as follow-up is concerned, the lower extremity is weighted with $20 \mathrm{~kg}$ for six weeks with the recommended successive increase in weight. Carrying weight on the upper extremity should be avoided for the same period. 
Moghaddam A et al.

Table 1. Score for Measuring an Individual's Risk of Developing a Non-Union (5)

\begin{tabular}{|c|c|c|c|}
\hline Sub-Item & \multicolumn{3}{|c|}{ Scores } \\
\hline \multicolumn{4}{|c|}{ Localization } \\
\hline Humerus & Prox. 4 points & Diaph. 6 points & Distal 2 points \\
\hline Forearm & Prox. 4 points & Diaph. 6 points & Distal 2 points \\
\hline Femur & Prox. 4 points & Diaph. 6 points & Distal 8 points \\
\hline Tibia & Prox. 6 points & Diaph. 8 points & Distal 4 points \\
\hline \multicolumn{4}{|c|}{ Soft Tissue } \\
\hline General & $1^{\circ}$ open 4 points & $2^{\circ}$ open 6 points & $3^{\circ}$ open 10 points \\
\hline General & Fasciotomy 4 points ${ }^{a}$ & Previous fracture 8 points ${ }^{a}$ & Neurological disorder 6 points $b$ \\
\hline \multicolumn{4}{|c|}{ Smoking } \\
\hline General & Smoker 15 points & Previous smoker 5 points & Non-smoker 0 points \\
\hline \multicolumn{4}{|c|}{ Comorbiditiy/Medication } \\
\hline General & NSAID 4 points & Bisphosphonate 6 points & Diabetes 4 points \\
\hline Type 1 & $<10$ points & Low risk & NA \\
\hline Type 2 & $10-20$ points & Middle risk & NA \\
\hline Type 3 & $>20$ points & High risk & NA \\
\hline
\end{tabular}

Abbreviations: diaph, diaphyseal; prox, proximal; NA, not available.

${ }^{\mathrm{a}}$ Affected bone.

$\mathrm{b}_{\text {Affected limb. }}$

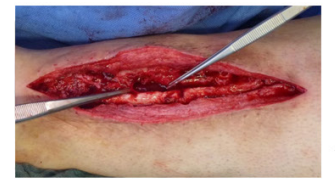

Vascularity

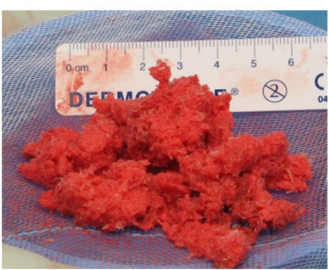

Osteogenic Cells

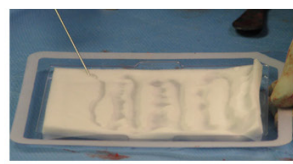

Osteoconductive Scaffolds
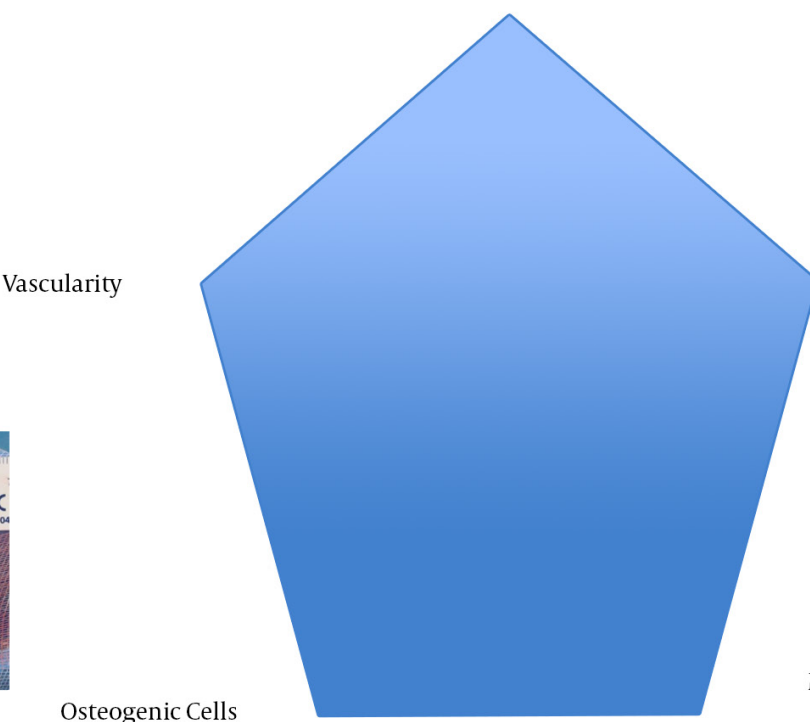

Growth Factors

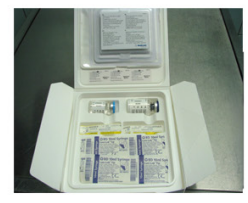

Mechanical Environment (ETN PROtect ${ }^{\mathrm{IM}}$ )

Figure 1. Factors of the Diamond Concept 
Moghaddam A et al.

\begin{tabular}{|c|c|c|}
\hline Criteria & Score $^{\mathrm{a}}$ & Max. Score \\
\hline \multicolumn{3}{|l|}{ The Bone } \\
\hline \multicolumn{3}{|l|}{ Quality of the bone } \\
\hline Good & 0 & NA \\
\hline Moderate (e.g. mildly osteoporotic) & 1 & NA \\
\hline Poor (e.g. severe porosis or bone loss) & 2 & NA \\
\hline Very poor (necrotic, appears avascular or septic) & 3 & 3 \\
\hline \multicolumn{3}{|l|}{ Primary injury - open or closed fracture } \\
\hline Closed & 0 & NA \\
\hline Open $1^{\circ}$ grade & 1 & NA \\
\hline Open $2-3^{\circ} \mathrm{A}$ grade & 3 & NA \\
\hline Open $3^{\circ} \mathrm{B}-\mathrm{C}$ grade & 5 & 5 \\
\hline \multicolumn{3}{|l|}{ Number of previous interventions on this bone to procure healing } \\
\hline None & 1 & NA \\
\hline$<2$ & 2 & NA \\
\hline$<4$ & 3 & NA \\
\hline$>4$ & 4 & 4 \\
\hline \multicolumn{3}{|l|}{ Invasiveness of previous interventions } \\
\hline Minimally-invasive: Closed surgery (screws, k wires) & 0 & NA \\
\hline Internal intra-medullary (nailing) & 1 & NA \\
\hline Internal extra-medullary & 2 & NA \\
\hline Any osteosynthesis which includes bone grafting & 3 & 3 \\
\hline \multicolumn{3}{|l|}{ Adequacy of primary surgery } \\
\hline Adequate stability & 0 & NA \\
\hline Inadequate stability & 1 & 1 \\
\hline \multicolumn{3}{|l|}{ Weber and cech group } \\
\hline Hypertrophic & 1 & NA \\
\hline Oligotrophic & 3 & NA \\
\hline Atrophic & 5 & 5 \\
\hline \multicolumn{3}{|l|}{ Bone alignment } \\
\hline Anatomic alignment & 0 & NA \\
\hline Non-anatomic alignment & 1 & 1 \\
\hline \multicolumn{3}{|l|}{ Bone defect - Gap } \\
\hline $0.5-1 \mathrm{~cm}$ & 2 & NA \\
\hline $1-3 \mathrm{~cm}$ & 3 & NA \\
\hline$>3 \mathrm{~cm}$ & 5 & 5 \\
\hline \multicolumn{3}{|l|}{ Soft Tissues } \\
\hline \multicolumn{3}{|l|}{ Status } \\
\hline Intact & 0 & NA \\
\hline Previous uneventful surgery, minor scarring & 2 & NA \\
\hline $\begin{array}{l}\text { Previous treatment of soft tissue defect (e.g. skin loss, local flap cover, multiple incisions, compartment syndrome, } \\
\text { old sinuses) }\end{array}$ & 3 & NA \\
\hline Previous complex treatment of soft tissue defect (e.g. free flap) & 4 & NA \\
\hline Poor vascularity: absence of distal pulses, poor capillary refill, venous insufficiency & 5 & NA \\
\hline Presence of actual skin lesion/defect (e.g. ulcer, sinus, exposed bone or plate) & 6 & 6 \\
\hline \multicolumn{3}{|l|}{ The Patient } \\
\hline \multicolumn{3}{|l|}{ ASA Grade } \\
\hline 1 or 2 & 0 & NA \\
\hline 3 or 4 & 1 & 1 \\
\hline Diabetes & & \\
\hline
\end{tabular}




\begin{tabular}{|c|c|c|}
\hline No & 0 & NA \\
\hline Yes - well controlled $($ HbA1c $<10)$ & 1 & NA \\
\hline Yes - poorly controlled (HbA1c >10) & 2 & 2 \\
\hline \multicolumn{3}{|l|}{ Blood tests: FBC, ESR, CRP } \\
\hline FBC: WCC $>12$ & 1 & NA \\
\hline $\mathrm{ESR}>20$ & 1 & NA \\
\hline $\mathrm{CRP}>20$ & 1 & 3 \\
\hline \multicolumn{3}{|l|}{ Clinical infection status } \\
\hline Clean & 0 & NA \\
\hline Previously infected or suspicion of infection & 1 & NA \\
\hline Septic & 4 & 4 \\
\hline \multicolumn{3}{|l|}{ Drugs } \\
\hline Steroids & 1 & NA \\
\hline NSAIDs & 1 & 2 \\
\hline \multicolumn{3}{|l|}{ Smoking status } \\
\hline No & 0 & NA \\
\hline Yes & 5 & 5 \\
\hline
\end{tabular}

Abbreviation: NA, not available.

${ }^{\mathrm{a}}$ Higher score implies a more-difficult-to-procure union.

Figure 2. Reamer Irrigator Aspirator Method
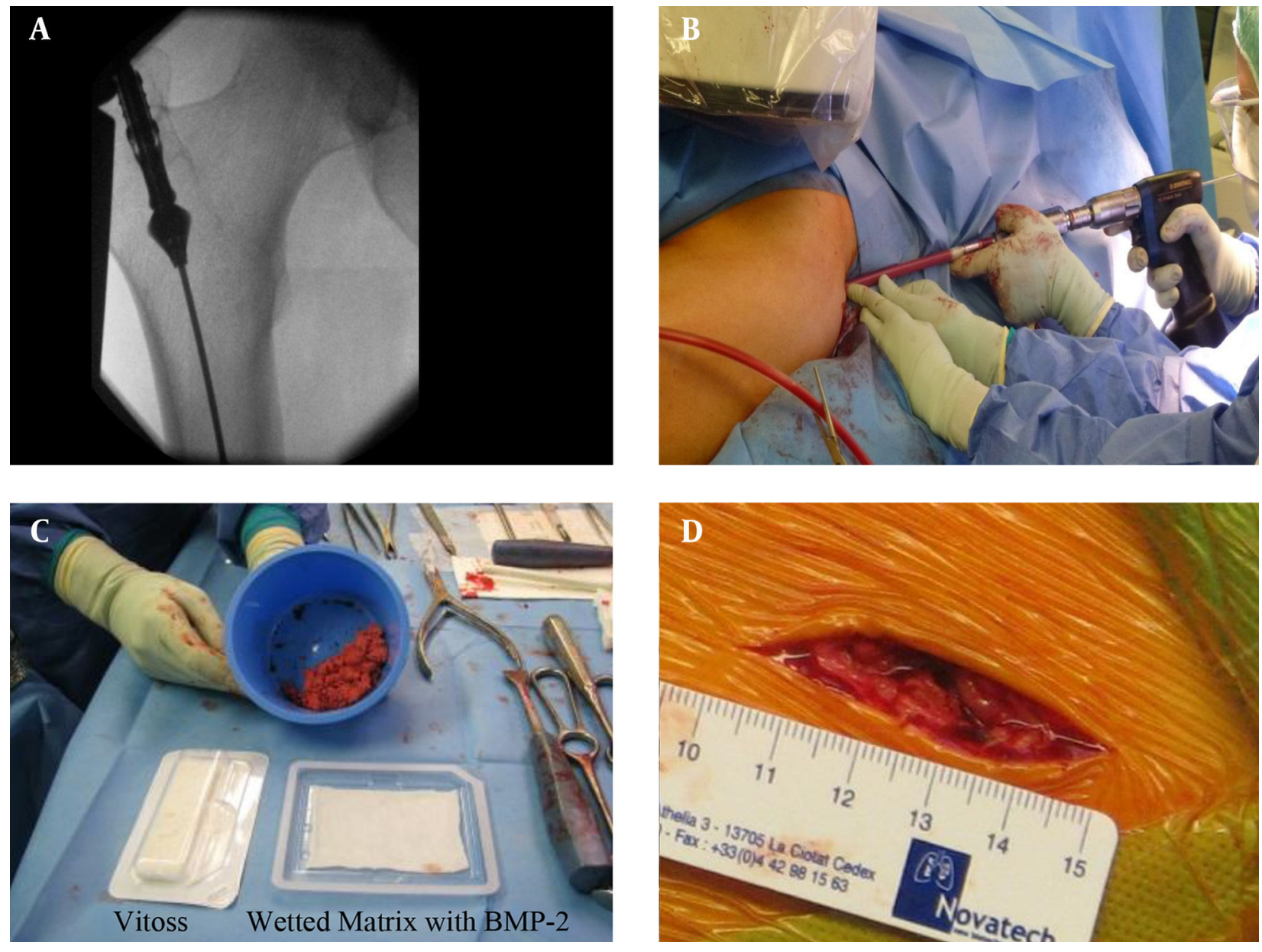

A, position control; B, reaming of left femur shaft by RIA; C, harvesting of autologous bone craft by RIA + BMP2 (materials: Vitoss and wetted matrix with BMP-2); D, skin incision for reamer: $4 \mathrm{~cm}$. 


\subsection{Soft Tissue Covering and Improvement of Vas- cularization}

Sufficient soft tissue covering and improvement of blood circulation of the affected extremity are necessary for successful non-union therapy and use of the above mentioned techniques (Figure 5). An interdisciplinary therapy concept in cooperation with plastic and vascular surgeons is meaningful and often necessary.

Ideally, complex cases should be discussed interdisciplinary and a therapy concept should be agreed upon, for example in an interdisciplinary extremity board. The chance of healing is higher with interventional angiography and sufficient soft tissue covering with a vascularized surgical flap e.g. anterolateral thigh (ALT) flap before definitive defect filling.

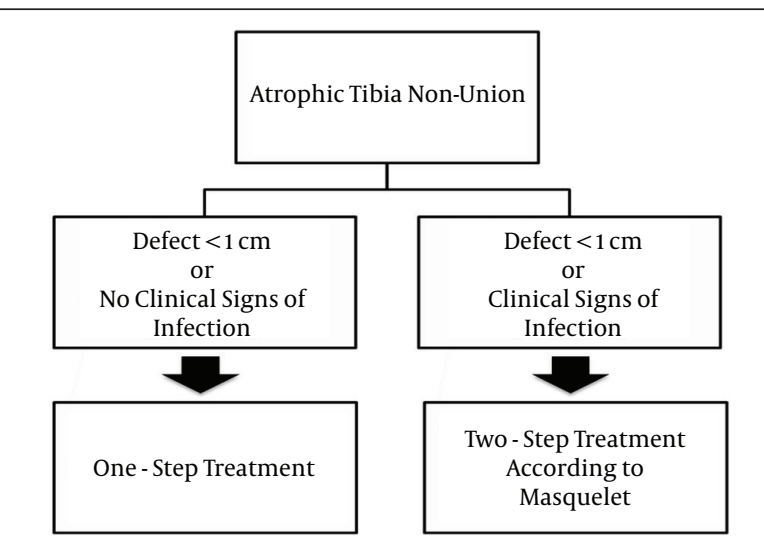

Figure 3. Diagram for Treatment Decisions (39)

Figure 4. Defect and Infection Non-Unions of the Tibia in the Masquelet Technique
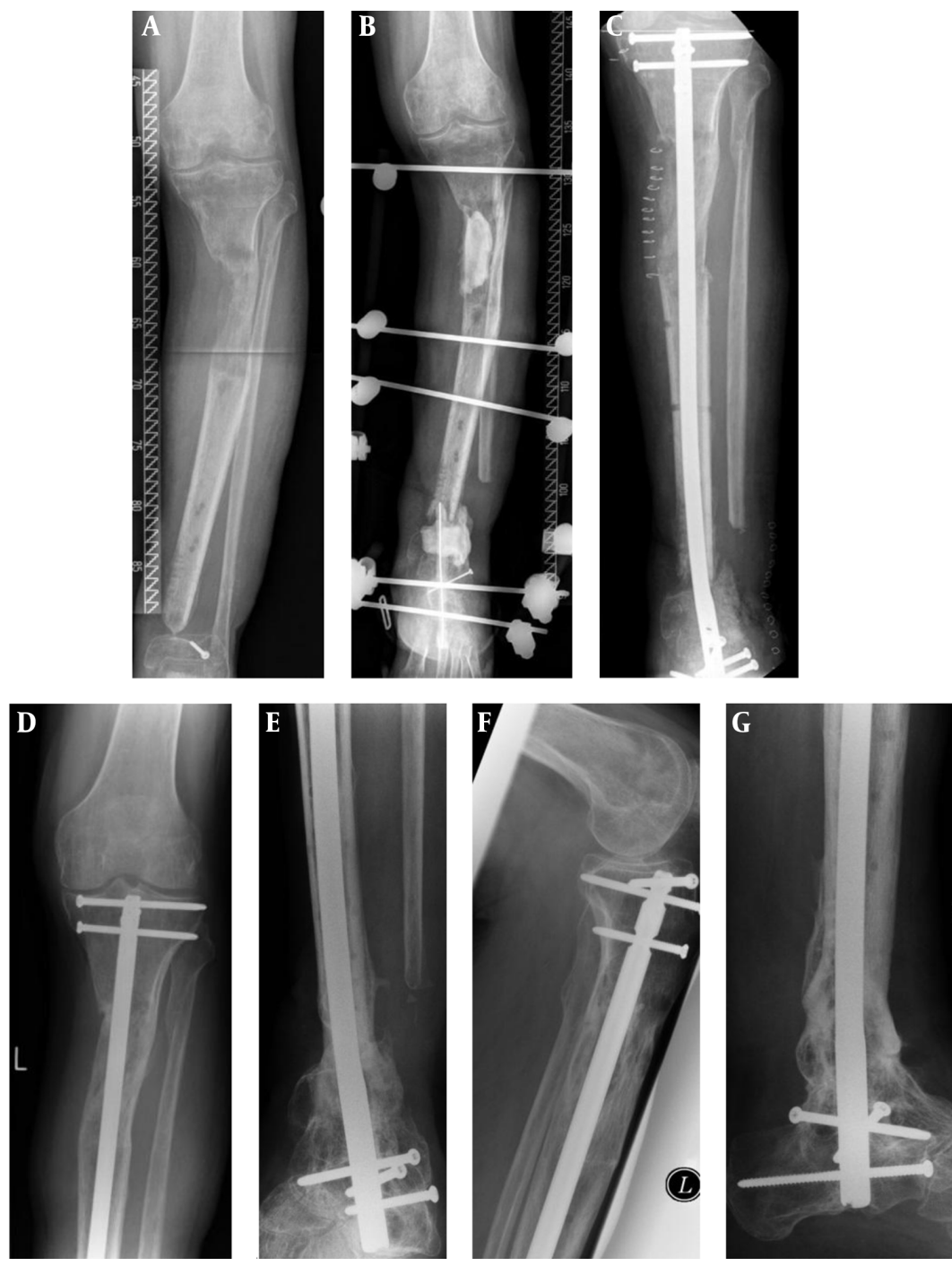

A, preoperatively step I, 04/2012; B, postoperatively step II, 04/2012; C, postoperative step II, 06/2012; D - G, recall postoperative, 03/2014. Case report: patient was treated with two-step Masquelet technique and diamond concept. Initial presentation: 11/2011. Patient: male, 72 years old. Infected non-union of the left tibia after $3^{\circ}$ open fracture. Status after resection and transport with Ilizarov fixateur. Risk factors: 19 previous surgeries, hypertonus, NSAID. 
Figure 5. Treatment of Osteitis of Chronic Tibia
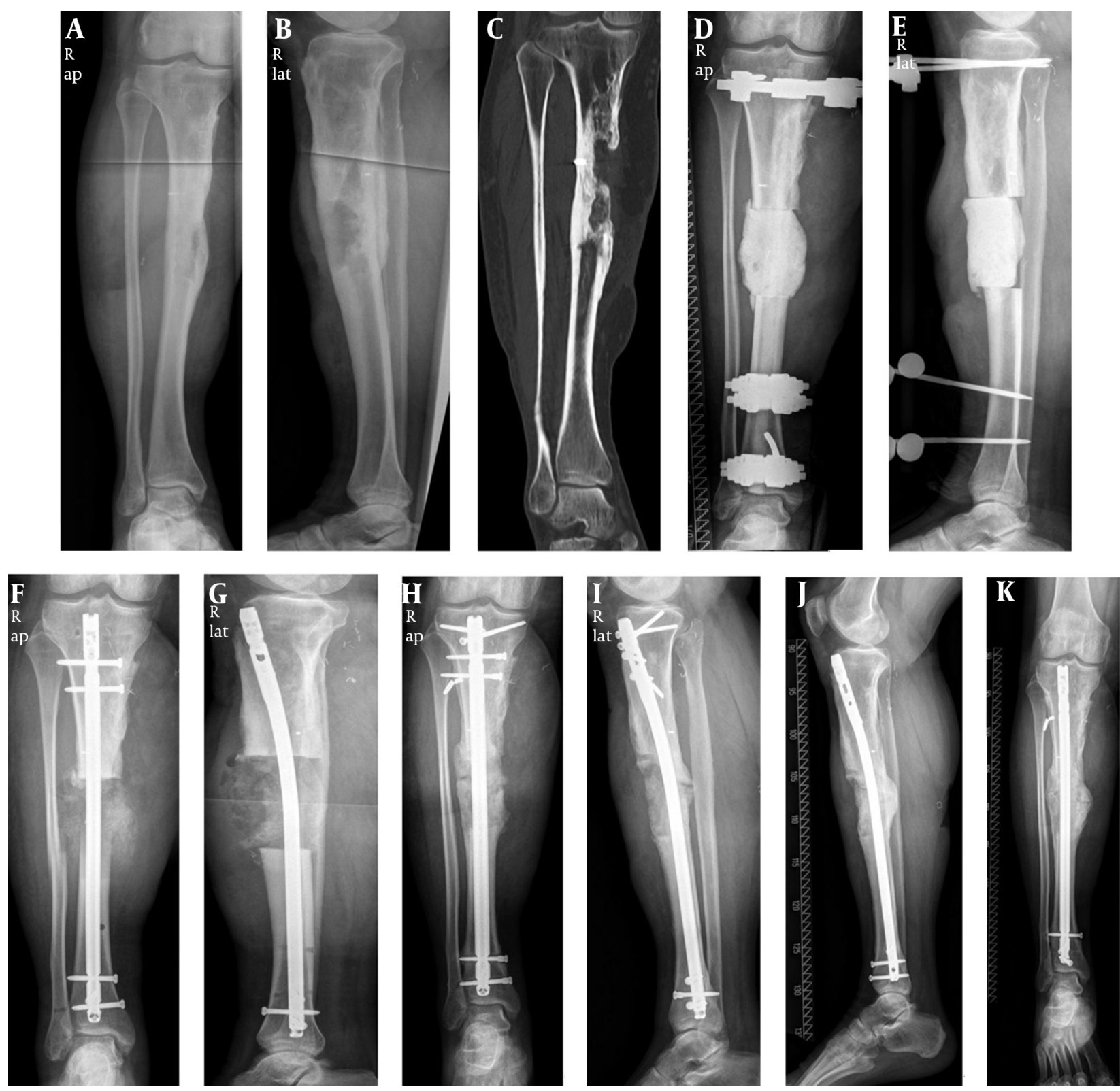

A - C, preoperatively; D and E, postoperative step I; F and G, postoperative step II; H and I, postoperative:1 year; J and K, recall postoperative: 2 years.

\section{Conclusions}

Through sufficient soft tissue management and stabile primary osteosynthesis, the development of a non-union can be avoided. A useful prophylaxis against infections and non-unions, especially in open lower leg fractures, is a combination of BMP-2 and antibiotic covered medullary nails (ETN PROtect) $(55,59,60)$.

In delayed fracture healing, there are simple techniques for improving the chances of bone consolidation such as raising weight bearing or the dynamization of static medullary nails.
In delayed fracture healing, consolidation can often be reached with simple measures such as increasing the load or dynamization of the statically locked medullary nail. Additionally, a local ultrasound treatment in the early phase of delayed fracture healing can be used.

If there are indications of an atrophic non-union, besides a reosteosynthesis, biological stimulation is necessary. In the first revision surgery, autologous transplantation of cancellous bone is often enough. Cancellous bone can be removed from the iliac crest; however, there are 
often complications and pain in the area. Alternatively, RIA can be taken out of the femur with lower extraction morbidity. Through correct placement of the guide wire, rare complications such as perforation or fracture of the femur can be avoided. If consolidation after cancellous bone is still not present, the further use of BMPs in combination with cancellous bone is indicated. In complex cases, consequential and radical removal of the infection often requires improved circulation through interventional angiography and use of the Masquelet technique as well as a tissue covering to avoid treatment failure. In complex cases, a close interdisciplinary team involving an extremity board comprised of an orthopedist/trauma surgeon, vascular surgeon, radiologist and plastic surgeons can be useful.

\section{Footnote}

Authors' Contribution:Study concept and design, analysis and interpretation of data, drafting of the manuscript, critical revision of the manuscript for important intellectual content and statistical analysis: Arash Moghaddam and Gerhard Schmidmaier. Correction of the paper: Claudia Ermisch.

\section{References}

1. Einhorn TA. The cell and molecular biology of fracture healing. Clin Orthop Relat Res. 1998;(355 Suppl):S7-21. [PubMed: 9917622]

2. Schmidmaier G, Schwabe P, Wildemann B, Haas NP. Use of bone morphogenetic proteins for treatment of non-unions and future perspectives. Injury. 2007;38 Suppl 4:S35-41. [PubMed: 18224735]

3. Giannoudis PV, Einhorn TA, Schmidmaier G, Marsh D. The diamond concept--open questions. Injury. 2008;39 Suppl 2:S5-8. doi: 10.1016/S0 020-1383(08)70010-X. [PubMed:18804574]

4. Rothman RH, Klemek JS, Toton JJ. The effect of iron deficiency anemia on fracture healing. Clin Orthop Relat Res. 1971;77:276-83. [PubMed: 5140454]

5. Moghaddam A, Zimmermann G, Hammer K, Bruckner T, Grutzner PA, von Recum J. Cigarette smoking influences the clinical and occupational outcome of patients with tibial shaft fractures. Injury. 2011;42(12):1435-42. doi: 10.1016/j.injury.2011.05.011. [PubMed: 21665205]

6. Keating JF, O'Brien PI, Blachut PA, Meek RN, Broekhuyse HM. Reamed interlocking intramedullary nailing of open fractures of the tibia. Clin Orthop Relat Res. 1997;(338):182-91. [PubMed: 9170379]

7. Clifford RP, Lyons TJ, Webb JK. Complications of external fixation of open fractures of the tibia. Injury. 1987;18(3):174-6. [PubMed: 3508844]

8. Ruedi TP, Luscher JN. Results after internal fixation of comminuted fractures of the femoral shaft with DC plates. Clin Orthop Relat Res. 1979;(138):74-6. [PubMed: 445920]

9. Wolinsky PR, McCarty E, Shyr Y, Johnson K. Reamed intramedullary nailing of the femur: 551 cases. J Trauma. 1999;46(3):392-9. [PubMed: 10088839]

10. Ricci WM, Bellabarba C, Evanoff B, Herscovici D, DiPasquale T, Sanders R. Retrograde versus antegrade nailing of femoral shaft fractures. J Orthop Trauma. 20 01;15(3):161-9. [PubMed:112650 05]

11. Kontakis GM, Papadokostakis GM, Alpantaki K, Chlouverakis G, Hadjipavlou AG, Giannoudis PV. Intramedullary nailing for nonunion of the humeral diaphysis: a review. Injury. 2006;37(10):95360. doi:10.1016/j.injury.2006.02.050. [PubMed: 16777105]

12. Rommens PM, Kuechle R, Bord T, Lewens T, Engelmann R, Blum J. Humeral nailing revisited. Injury. 2008;39(12):1319-28. doi: 10.1016/j.injury.2008.01.014. [PubMed: 18417134]
13. Wright RR, Schmeling GJ, Schwab JP. The necessity of acute bone grafting in diaphyseal forearm fractures: a retrospective review. J Orthop Trauma.1997;11(4):288-94. [PubMed:9258828]

14. Wei SY, Born CT, Abene A, Ong A, Hayda R, DeLong WG, Jr. Diaphyseal forearm fractures treated with and without bone graft. $J$ Trauma.1999;46(6):1045-8. [PubMed: 10372622]

15. Ring D, Allende C, Jafarnia K, Allende BT, Jupiter JB. Ununited diaphyseal forearm fractures with segmental defects: plate fixation and autogenous cancellous bone-grafting. J Bone Joint Surg Am. 2004;86-a(11):2440-5. [PubMed:15523016]

16. Richard MJ, Ruch DS, Aldridge JM, 3rd. Malunions and nonunions of the forearm. Hand Clin. 2007;23(2):235-43. doi: 10.1016/j. hcl.2007.02.005. vii. [PubMed:17548014]

17. Krzykawski R, Krol R, Kaminski A. The results of locked intramedullary nailing for non-union of forearm bones. Ortop Traumatol Rehabil. 2008;10(1):35-43. [PubMed: 18391904]

18. Moghaddam-Alvandi A,Zimmermann G, Buchler A, Elleser C, Biglari $B$, Grutzner PA, et al. [Results of nonunion treatment with bone morphogenetic protein 7 (BMP-7)]. Unfallchirurg. 2012;115(6):518-26. doi: 10.1007/s00113-011-2100-0. [PubMed: 22476375]

19. Gaston MS, Simpson AH. Inhibition of fracture healing.JBone Joint Surg Br. 2007;89(12):1553-60. doi: 10.1302/0301-620X.89B12.19671. [PubMed: 18057352]

20. Moghaddam A, Weiss S, WolflCG, Schmeckenbecher K, Wentzensen A, Grutzner PA, et al. Cigarette smoking decreases TGF-b1 serum concentrations after long bone fracture. Injury. 2010;41(10):1020-5. doi:10.1016/j.injury.2010.03.014. [PubMed:20471641]

21. McKibbin B. The biology of fracture healing in long bones.J Bone Joint Surg Br. 1978;60-B(2):150-62. [PubMed: 350882]

22. Tonna EA. Histologic and histochemical studies on the periosteum of male and female rats at different ages. J Gerontol. 1958;13(1):14-9. [PubMed:13514031]

23. Macey LR, Kana SM, Jingushi S, Terek RM, Borretos J, Bolander ME. Defects of early fracture-healing in experimental diabetes.J Bone Joint Surg Am. 1989;71(5):722-33. [PubMed: 2659600]

24. Cruess RL, Sakai T. Effect of cortisone upon synthesis rates of some components of rat bone matrix. Clin Orthop Relat Res. 1972;86:253-9. [PubMed: 4261729]

25. Schoierer O, Bloess K, Bender D, Burkholder I, Kauczor HU, Schmidmaier G, et al. Dynamic contrast-enhanced magnetic resonance imaging can assess vascularity within fracture nonunions and predicts good outcome. Eur Radiol. 2014;24(2):44959. doi: 10.1007/s00330-013-3043-3. [PubMed: 24145951]

26. Bode G, Strohm PC, Sudkamp NP, Hammer TO. Tibial shaft fractures - management and treatment options. A review of the current literature. Acta Chir Orthop Traumatol Cech. 2012;79(6):499505. [PubMed: 23286681]

27. Calori GM, Phillips M, Jeetle S, Tagliabue L, Giannoudis PV. Classification of non-union: need for a new scoring system? Injury. 2008;39 Suppl 2:S59-63. doi: 10.1016/s0 020-1383(08)70016-0. [PubMed: 18804575]

28. Abumunaser LA, Al-Sayyad MJ. Evaluation of the calori et Al nonunion scoring system in a retrospective case series. Orthopedics. 2011;34(5):359. doi:10.3928/01477447-20110317-31. [PubMed:21598896]

29. Pneumaticos SG, Panteli M, Triantafyllopoulos GK, Papakostidis C, Giannoudis PV. Management and outcome of diaphyseal aseptic nonunions of the lower limb: a systematic review. Surgeon. 2014;12(3):16675. doi:10.1016/j.surge.2013.10.007. [PubMed: 24309558]

30. Calori GM, Colombo M, Mazza EL, Mazzola S, Malagoli E, Marelli $\mathrm{N}$, et al. Validation of the Non-Union Scoring System in 300 long bone non-unions. Injury. 2014;45 Suppl 6:S93-7. doi: 10.1016/j.injury.2014.10.030. [PubMed: 25457326]

31. Roussignol X, Currey C, Duparc F, Dujardin F. Indications and results for the Exogen ultrasound system in the management of non-union: a 59-case pilot study. Orthop Traumatol Surg Res. 2012;98(2):206-13.doi:10.1016/j.otsr.2011.10.011.[PubMed:22424956]

32. Giannoudis PV, Einhorn TA, Marsh D. Fracture healing: the diamond concept. Injury. 2007;38 Suppl 4:S3-6. [PubMed:18224731]

33. Calori GM, Colombo M, Mazza E, Ripamonti C, Mazzola S, Marelli $\mathrm{N}$, et al. Monotherapy vs. polytherapy in the treatment of forearm non-unions and bone defects. Injury. 2013;44 Suppl 1:S63-9. doi:10.1016/S0020-1383(13)70015-9. [PubMed: 23351875] 
34. Giannoudis PV, Calori GM, Begue T, Schmidmaier G. Bone regeneration strategies: current trends but what the future holds? Injury. 2013;44 Suppl 1:S1-2. doi: 10.1016/S0 020-1383(13)70002-0. [PubMed: 23351862]

35. Giannoudis PV, Ahmad MA, Mineo GV, Tosounidis TI, Calori GM, Kanakaris NK. Subtrochanteric fracture non-unions with implant failure managed with the "Diamond" concept. Injury. 2013;44 Suppl 1:S76-81. doi: 10.1016/S0020-1383(13)70017-2. [PubMed: 23351877]

36. Calori GM, Colombo M, Ripamonti C, Bucci M, Fadigati P, Mazza E, et al. Polytherapy in bone regeneration: clinical applications and preliminary considerations. Int J Immunopathol Pharmacol. 2011;24(1 Suppl 2):85-90. [PubMed: 21669144]

37. Pountos I, Georgouli T, Pneumaticos S, Giannoudis PV. Fracture non-union: Can biomarkers predict outcome? Injury. 2013;44(12):1725-32. doi: 10.1016/j.injury.2013.09.009. [PubMed: 24075219]

38. Calori GM, Giannoudis PV. Enhancement of fracture healing with the diamond concept: the role of the biological chamber. Injury. 2011;42(11):1191-3. doi:10.1016/j.injury.2011.04.016. [PubMed: 21596376]

39. Moghaddam A, Zietzschmann S, Bruckner T, Schmidmaier G. Treatment of atrophic tibia non-unions according to 'diamond concept': Results of one- and two-step treatment. Injury. 2015;46 Suppl 4:S39-50. doi: 10.1016/S0020-1383(15)30017-6. [PubMed: 26542865]

40. Giannoudis PV, Jones E, Einhorn TA. Fracture healing and bone repair. Injury. 2011;42(6):549-50. doi: 10.1016/j.injury.2011.03.037. [PubMed: 21474131]

41. Schmidmaier G, Schwabe P, Strobel C, Wildemann B. Carrier systems and application of growth factors in orthopaedics. Injury. 2008;39 Suppl 2:S37-43. doi: 10.1016/S0020-1383(08)70014-7. [PubMed: 18804572]

42. Dinopoulos C. Re: The article "Dinopoulos H, Dimitriou R, Giannoudis PV. Bone graft substitutes: what are the options? Surgeon. 2012 Aug;10(4):230-9. Surgeon. 2013;11(5):293. doi: 10.1016/j. surge.2013.05.008. [PubMed: 23932800]

43. Kouroupis D, Baboolal TG, Jones E, Giannoudis PV. Native multipotential stromal cell colonization and graft expander potential of a bovine natural bone scaffold. J Orthop Res. 2013;31(12):1950-8. doi:10.1002/jor.22438. [PubMed: 23868185]

44. Kanakaris NK, Morell D, Gudipati S, Britten S, Giannoudis PV. Reaming Irrigator Aspirator system: early experience of its multipurpose use. Injury. 2011;42 Suppl 4:S28-34. doi: 10.1016/S00201383(11)70009-2. [PubMed:21939800]

45. Cox G, McGonagle D, Boxall SA, Buckley CT, Jones E, Giannoudis PV. The use of the reamer-irrigator-aspirator to harvest mesenchymal stem cells. J Bone Joint Surg Br. 2011;93(4):517-24. doi: 10.1302/0301-620X.93B4.25506. [PubMed: 21464493]

46. Schmidmaier G, Moghaddam-Alvandi A. [cited 2015 10.06]; Was gibt es Neues 2014 in der Pseudarthrosen-Therapie? 2014 Available from: http://www.ecme-center.org/WebObjects/ECMECenter. woa $/ \mathrm{cms} / 1001057 /$ Kurssuche.html?courseDetails=1003662.

47. Cuthbert R, Boxall SA, Tan HB, Giannoudis PV, McGonagle D, Jones
E. Single-platform quality control assay to quantify multipotential stromal cells in bone marrow aspirates prior to bulk manufacture or direct therapeutic use. Cytotherapy. 2012;14(4):431-40. doi:10.3109/14653249.2011.651533. [PubMed: 22268519]

48. Fayaz HC, Giannoudis PV, Vrahas MS, Smith RM, Moran C, Pape $\mathrm{HC}$, et al. The role of stem cells in fracture healing and nonunion. Int Orthop. 2011;35(11):1587-97. doi: 10.1007/s00264-011-1338-z. [PubMed: 21863226]

49. Blokhuis TJ, Calori GM, Schmidmaier G. Autograft versus BMPs for the treatment of non-unions: what is the evidence? Injury. 2013;44 Suppl 1:S40-2. doi: 10.1016/S0020-1383(13)70009-3. [PubMed: 23351869]

50. Schmidmaier G, Herrmann S, Green J, Weber T, Scharfenberger A Haas NP, etal. Quantitative assessment of growth factors in reaming aspirate, iliac crest, and platelet preparation. Bone. 2006;39(5):115663. doi:10.1016/j.bone.2006.05.023. [PubMed:16863704]

51. Calori GM, Colombo M, Mazza EL, Mazzola S, Malagoli E, Mineo GV. Incidence of donor site morbidity following harvesting from iliac crest or RIA graft. Injury. 2014;45 Suppl 6:S116-20. doi: 10.1016/j.injury.2014.10.034. [PubMed: 25457330]

52. Schmidmaier G, Wildemann B. The role of BMPs in current orthopedic practice. IBMS BoneKEy. 2009;6(7):244-53. doi: $10.1138 / 20090386$

53. Giannoudis PV, Kanakaris NK, Dimitriou R, Gill I, Kolimarala V, Montgomery RJ. The synergistic effect of autograft and BMP-7 in the treatment of atrophic nonunions. Clin Orthop Relat Res. 2009;467(12):3239-48. doi: 10.1007/s11999-009-0846-2. [PubMed: 19396502]

54. Aymar M, Ewerbeck V. Standardverfahren in der Operativen Orthopädie und Unfallchirurgie. In: Uberarb V, Aufl E, editors. 4 ed. New York: Thieme, Stuttgart; 2014. p. 898.

55. Schmidmaier G, Lucke M, Wildemann B, Haas NP, Raschke M. Prophylaxis and treatment of implant-related infections by antibiotic-coated implants: a review. Injury. 2006;37 Suppl 2:S105-12. doi:10.1016/j.injury.2006.04.016. [PubMed:16651063]

56. Giannoudis PV, Chris Arts JJ, Schmidmaier G, Larsson S. What should be the characteristics of the ideal bone graft substitute? Injury. 2011;42 Suppl 2:S1-2. doi: 10.1016/j.injury.2011.06.001. [PubMed: 21700284]

57. Janicki P, Schmidmaier G. What should be the characteristics of the ideal bone graft substitute? Combining scaffolds with growth factors and/or stem cells. Injury. 2011;42 Suppl 2:S77-81. doi:10.1016/j.injury.2011.06.014. [PubMed: 21724186]

58. Schmidmaier G, Capanna R, Wildemann B, Beque T, Lowenberg D. Bone morphogenetic proteins in critical-size bone defects: what are the options? Injury. 2009;40 Suppl 3:S39-43. doi: 10.1016/s0020-1383(09)70010-5. [PubMed:20082789]

59. Fuchs T, Stange R, Schmidmaier G, Raschke MJ. The use of gentamicin-coated nails in the tibia: preliminary results of a prospective study. Arch Orthop Trauma Surg. 2011;131(10):1419-25. doi: 10.1007/s00402-011-1321-6. [PubMed: 21617934]

60. Fuchs T, Schmidmaier G, Raschke MJ, Stange R. Bioactive-Coated Implants in Trauma Surgery. Eur I Trauma Emergency Surg. 2007;34(1):60-8. doi: 10.1007/s00068-006-6110-5. 